Title:

\title{
Spatial risk model and mitigation implications for wolf-human conflict in a highly modified agroecosystem in western Iran
}

\author{
Authors: \\ Neda Behdarvand ${ }^{\text {a }}$, Mohammad Kaboli ${ }^{a^{*}}$, Mohsen Ahmadi ${ }^{\text {a }}$, Elham Nourani ${ }^{\text {a }}$, Abdolrassoul \\ Salman Mahini ${ }^{\mathrm{b}}$, Marzieh Asadi Aghbolaghi ${ }^{\mathrm{a}}$
}

Affiliations and addresses:

${ }^{a}$ Department of Environmental Sciences, Faculty of Natural Resources, University of Tehran, Karaj, Iran

${ }^{b}$ Department of the Environment, Faculty of Fishery and Environment, Gorgan University of Agriculture and Natural Resources Sciences, Golestan province, Gorgan, Iran

\section{"Corresponding Author: MOHAMMAD KABOLI}

Tel: +98-2632223044; Fax: +98-2632229721; $\quad$ Email: mkaboli@ut.ac.ir 


\begin{abstract}
Human-carnivore conflict is hampering carnivore conservation worldwide. Conflicts between humans and wolves (Canis lupus) in western Iran, especially Hamedan province (HP), occur in the form of livestock depredation and predatory attacks on people. These conflicts have become a major concern for the lives and livelihoods of the local people as well as an obstacle for conservation of the wolf. To determine the most important predictors of such conflicts and to identify the distribution of areas with potential risk of wolf attack on humans and livestock in HP, we employed maximum entropy (Maxent) algorithm to build predictive models with reported conflict data from 2001 to 2010 . The resulting models correctly assigned subsequent attack sites from 2011 and 2012 to high-risk areas. We found that variables related to land use/cover types affected by anthropogenic influences on the landscape, such as irrigated farms and human settlements, were the most important in predicting wolf attack risk levels. The risk maps developed in this study are useful tools for identifying conflict hotspots and facilitate policymaking and action planning for conflict mitigation in western Iran.
\end{abstract}

Keywords: Conflict mitigation, livestock depredation, predatory attack, risk map.

\title{
1. Introduction
}

The rapid growth of human population and consequently the increase in resource use and habitat destruction have exacerbated the problem of human-wildlife conflicts throughout the world (Graham et al. 2005; Holmern et al. 2007; Treves et al. 2004). In particular, large predators are subject to such conflicts due to their large home ranges that overlap with human distributions and 
their dietary requirements that attract them to human settlements and food sources (Iftikhar Dar et al. 2009; Linnell et al. 2001; Treves and Karanth 2003). This can threaten human lives and livelihoods (Gurung et al. 2008; Iftikhar Dar et al. 2009; Michalski et al. 2006; Sidorovich et al. 2003; Vos 2000) and build negative attitudes toward carnivores, leading to extermination of carnivore populations by local people (Sacks et al. 1999; Sillero-Zubiri and Switzer 2004).

Understanding carnivore-human conflict has become an important concern in the scientific community. The majority of carnivore-human conflicts in the world is attributed to livestock depredation (Graham et al. 2005). This is a common problem especially in range countries of the wolf (Canis lupus) and is usually mitigated by compensation programs (Bostedt and Grahn 2008; Breck et al. 2011; Muhly and Musiani 2009) and improvements in husbandry techniques (Ciucci and Boitani 1998; Mishra 1997). However, wolf attacks on humans, which are relatively rare worldwide (Linnell et al. 2002; Linnell et al. 2003), cannot be compensated for and prevention remains the best approach for their mitigation.

Globally, wolf attacks on humans are classified into three types (Linnell et al. 2002). The majority of attacks are attributed to rabid wolves. The second type involves animals provoked by human interventions (traps, persecution of pups, and destruction of dens). These attack types are unpredictable and incidental in nature (Linnell et al. 2002). The rarest of all wolf attacks are nonrabid predatory attacks, with animals involved mostly identified as wolf-dog hybrids. Hybrids generally have less fear of humans than wild wolves (Linnell et al. 2002; McNay and Hicks 2002), and are more likely to live in the vicinity of human settlements. This type of attack has been reported from countries including Spain, India, Lithuania, and Italy (Mech and Boitani 2010). 
The wolf in Iran was once widely distributed through the country, except in the deserts, but has been heavily persecuted as a response to the increasing level of conflict with rural communities (Ziaie 2008). The problem has escalated in recent years mainly due to the expansion of agriculture and other anthropogenic activities, creating a human-dominated landscape that is particularly evident in western Iran (Imani Harsini 2012). Although wolf attacks on humans were historically quite rare and death incidents were even less frequent, an increase in fatal attacks on humans in recent years reveals a high level of wolf-human conflict in Hamedan Province (HP), reaching a peak of 10 attacks in summer 2010 (DOE Hamedan Provincial Office, unpublished reports). Tests for rabies (DOE Hamedan Provincial Office, unpublished reports) and hybridization (Khosravi et al. 2013) have been negative, and thus attacks in HP can generally be categorized as predatory attacks made by hungry wolves (Behdarvand \& Kaboli, in press). With increased wolf-human conflicts in the province, local peoples' tendency to exterminate wolves and wolf pups has increased (DOE Hamedan Provincial Office, unpublished data), making conflict mitigation a high priority for the local government.

An important criterion for the success of wolf-human conflict management, and consequently the conservation of wolves, is maintaining such conflicts at a low level (Iftikhar Dar et al. 2009). Achieving this goal can be challenging in multi-use landscapes inhabited by people and wolves (Edge et al. 2011; Löe and Röskaft 2004; Northrup et al. 2012). However, since such conflicts are distributed in non-random patterns (Treves et al. 2011; Wydeven et al. 2004), predictive spatial models, or risk maps, can be used for determining possible conflict locations. Risk maps provide a chance for early warning and targeted prevention of predator damage to humans and livestock (Iftikhar Dar et al. 2009; Jones et al. 2008; Kaartinen et al. 2009; Löe and Röskaft 2004; Treves et al. 2004; Venette et al. 2010; Wydeven et al. 2004). 
We developed risk maps for wolf attacks to livestock and humans in HP to (i) identify environmental parameters associated with wolf attacks on humans and livestock in the province and (ii) provide mitigation recommendations for such conflicts. We were especially concerned with detecting the influence of land use types in the highly modified human-dominated landscapes.

\section{Material and Methods}

\subsection{Study area}

The present study was conducted in HP, western Iran (47 $34^{\prime}-49^{\circ} 36^{\prime} \mathrm{E}, 33^{\circ} 59^{\prime}-35^{\circ} 48^{\prime} \mathrm{N}$; Fig. A1). Mean annual temperature ranges between $-4^{\circ} \mathrm{C}$ (January - February) to $35^{\circ} \mathrm{C}$ (July August). Mean annual rainfall is about $300 \mathrm{~mm}$ distributed unevenly in different months of the year. The province encompasses approximately $19493 \mathrm{~km}^{2}$ and supports a population of over two million people. Hamedan province is characterized by a human-dominated landscape with a mean human population density of about 88 inhabitants per $\mathrm{km}^{2}$, twice the mean population density in the country. The landscape is dominated by rangelands (33\%) and croplands (32\%), whereas mixed deciduous forest covered by Persian oak (Quercus brantii), hawthorn (Crataegus spp.) and cherry plum (Prunus divaricata) make up only $2 \%$ of the province. These patches of natural forest are distributed within an agricultural matrix of orchards, intensive irrigated farms of potato and corn and scattered dry farms of cereal crops. There are six protected areas in the province $\left(62 \mathrm{~km}^{2}\right)$, comprising a combination of mountainous habitats, undulating hills, and plains. The vegetation cover and low levels of human disturbance in these areas provide suitable habitat for the major ungulate prey for wolves in the study area, including wild goat (Capra 
aegagrus), wild sheep (Ovis orientalis) and wild boar (Sus scrofa). Economic activities in the region consist mainly of livestock rearing and agriculture (Reyahi Khoram and Fotros 2011). Livestock husbandry is an important source of income for local people in the province and consists of herds of sheep and goat freely grazing in fields and rangelands, watched over by a couple of shepherds (including children) and native guard dogs. Livestock are gathered at night and kept in covered pens either in villages or on rangelands.

\subsection{Conflict locations}

Between 2001 and 2010, 47 incidents of wolf attack on people, mostly children (70\%), and 57 incidents of wolf attack on livestock were documented (DOE Hamedan Provincial Office, unpublished data). A large number of attacks on humans and livestock were fatal while in others, the offending wolf was scared off or killed after injuring the victim (Behdarvand \& Kaboli, in press). Documentation of wolf depredation on livestock is commonly done in Iran for compensation purposes. Insurance companies compensate for livestock injuries and loss due to various causes, including depredation by wolves. In cases of attacks on humans that lead to lives lost, the Department of Environment pays a refund to families to prevent negative and vengeful attitudes towards wildlife in general and wolves in particular. Governors of rural districts immediately report all such attacks to DOE, which is responsible for determining the cause of the attack. Other than the wolf, hyenas are the only large wild carnivores in the area and DOE rangers and officials differentiate the attacks by examining animal signs at the attack site and types of wound and damage on the victim or prey, as well as through interviewing eyewitnesses and, in case of attack to humans, the survivors. In some cases, the offending wolf is killed by local people on site and DOE confirms the wolf attack by identifying the carcass as belonging to a wolf. However, in some instances, especially when victims or prey are assumed to be taken by 
the wolf but no sign of them can be found, there is not enough evidence for the DOE to confirm the attack.

We recorded the locations of confirmed wolf attack sites in the field by compiling a list of attack sites based on previous work by Behdarvand \& Kaboli (In press) as well as data provided by the DOE. We visited the villages mentioned in the list and subsequently located and recorded 88 of the 105 documented attack sites (31 locations of attack on people and 57 locations of livestock depredation; Fig. 1) through interviews with local people and DOE rangers.

To determine whether attacks to livestock and humans are spatially correlated, we divided the study area into $14 \times 14 \mathrm{~km}^{2}$ grids and the number of cells that contained wolf attack records was arranged into a contingency table. Cell size was selected based on empirical values of the nearest neighbor distance for breeding wolves as a value of the extent of wolf pack activity and calculated based on Jędrzejewski et al. (2004). Next, using the contingency table and Chi-square test, the probability of the independence of wolf attacks on humans from attacks on livestock was determined.

\subsection{Environmental predictor variables}

A set of variables known to be important predictors of wolf-human conflict was selected by reviewing relevant literature (Eggermann et al. 2011; Mladenoff et al. 1999; Norris et al. 2002). Although the distribution range of wolf packs is an important affecting variable in predicting wolf-human conflicts (Treves et al. 2011; Wydeven et al. 2004), the lack of long-term studies on wolf ecology that would provide direct or indirect measures of wolf territory in the study area confined us to omit biological aspects of wolf packs from our modeling. However, we included a data layer of areas of high probability of wolf denning (Ahmadi et al. 2013). Since these areas 
are of special interest to wolves throughout the year, they are identified as centers of wolf aggregation (Trapp et al. 2008; Unger et al. 2009) and were included as an index of wolf pack distribution in HP.

Environmental predictors that we used included land cover characteristics, distance to waterway (streams and rivers; perennial and non-perennial), distance to roads, topography-related variables, livestock density, human population density, wolf denning probability, and distance to protected areas (Table A1).

Land cover variables included rangeland (including bushland and grassland), rangeland with scattered crops, rocky and bare land, dry farms, and irrigated farms. Land use and cultivation types were taken into account in detail because they describe the amount of human activity in the landscape. The proportion of each cover type was calculated by running the ArcGIS 9.3 (ESRI INC 2008) Spatial Analyst neighborhood analysis over a three-kilometer radius. We chose this three-km buffer size based on literature review (e.g. Larsen and Ripple 2006; Belongie 2008), which well-describes landscape characterization over a wide geographic range.

We also calculated distance to human settlements, including cities and villages identifiable on 30-m-resolution Landsat image which was used to produce the land cover map. Land cover data were obtained from the Iranian Forests, Range and Watershed Management Organization (IFRWO) National Land Cover map. This data was derived from 30 m Landsat Enhanced Thematic Mapper Plus (ETM+) imagery for the conterminous Iran in the year 2010.

It is believed that livestock comprise a great proportion of wolf diet in human-dominated landscapes (Eggermann et al. 2011; Llaneza et al. 2012). Accordingly, the most important food source for wolves in the study area could be livestock, mainly cattle, sheep, and goats. Wild 
ungulates (i.e. game species), particularly wild sheep, wild goat, and wild boar can also be important. However, since their populations in HP are limited to protected areas and there are no precise estimates of their number and distribution, we included proximity to protected areas as an index of wild ungulate availability in our analyses. Overall, we estimated food availability as the density of domestic ungulates and distance to protected areas within the study area. Data on livestock density was obtained from government sectors at HP for each village. We used Inverse Weighted Distance function of ArcGIS 9.3 (Schuette et al. 2013) to interpolate livestock density into a raster layer.

We also considered elevation and topographic roughness as the most determinant physiographic parameters. Since the study area lacks suitable vegetation (e.g. scrublands, woodlands and forest) to effectively conceal wolves, rough terrains probably provide the necessary concealment for wolf movement (Ahmadi et al. 2013). For each point of the landscape, roughness was estimated as the standard deviation of the elevation of all raster cells over the three-kilometer radius.

All maps were prepared with a spatial resolution of $100 \mathrm{~m}$ in ArcGIS 9.3 (ESRI INC 2008). We calculated correlation coefficients to avoid multicollinearity between variables. None of the variables were highly correlated $(|r|>0.80$; Northrup et al., 2012), therefore all the aforementioned variables were applied in the modeling process.

\subsection{Modeling wolf attacks}

To determine the potential high risk areas and to identify the environmental features associated with wolf attacks on livestock and people in HP, we performed Maximum Entropy Analysis using Maxent v.3.3.3 software (Phillips et al. 2006). Maxent, often highlighted as one of the most effective presence-only models (Elith et al. 2011; Phillips et al. 2006), is a machine-learning 
process that can be used to estimate species distribution by finding the probability distribution of maximum entropy (i.e. closest to uniform) for an area under a specified set of environmental constraints.

We built our models separately for attacks on livestock and humans. Maxent was run applying default values for convergence threshold $\left(10^{-5}\right)$, maximum iterations (500), a regularization multiplier of 1, and 10,000 background points as these settings have proven to provide good performance in many cases (Phillips and Dudík 2008).

During Maxent run the "gain" was calculated as the probability distribution of the model that represents how closely the model is concentrated around the presence samples compared with random background pixels of study area. Since Maxent can be prone to overfitting the training data, especially with small sample size (Phillips et al., 2006), models are developed using the regularization that in a parsimonious procedure focuses on the most important variables (Phillips et al., 2006). To ease the conceptualization of the probability map, logistic output, with an estimate between 0 and 1 for probability of attack, was generated for each risk map.

It is worth mentioning that Maxent is the most capable modeling method in producing useful results with sample sizes of less than 25 occurrences (Hernandez et al. 2006; Pearson et al. 2007).To make better use of the small sample size of wolf attacks in HP, we used the crossvalidation method in Maxent. Instead of extracting a training-test dataset from the data, all of the wolf attack points were used to build Maxent model. Wolf attack sites were randomly split into 10 folds containing equal number of occurrences, and training models were created by eliminating each fold in turn. The removed fold was then used for testing the model derived from 
the remaining training folds. We used the area under receiver-operating characteristic curve (AUC), calculated for test folds, to evaluate models derived from training folds.

Moreover, Maxent provides an analysis of the percentage of contribution of each variable to the model building process, which helps to determine the influence of each variable on the model output. We also evaluated variable importance for our models by performing a jackknife analysis in Maxent software. In the jackknife procedure, we calculated the loss in regularized training gain of models when each variable was sequentially omitted. We also estimated obtained gain for each variable when used alone in the model. Subsequently, by considering the regularized training gains, the most important variables were determined.

Maxent calculates some thresholds to categorize continuous probability maps into suitable/unsuitable classes. This is more important when identifying suitable habitats and applying management activity is inevitable (Phillips et al. 2006). By using cross-validation method for resampling, Maxent provides a number of thresholds for each cross-validated fold which will cause ambiguity to choose a single threshold to categorize the concluding probability map. Furthermore, addressing areas with absolute possibility of wolf attack is unlikely. Herein, we categorized the continuous probability maps to five classes representing probability cutoffs in $20 \%$ increments. We hypothesized that areas encompassed within high probability classes will be faced with higher probability of wolf attacks.

We then used data on wolf attacks occurring in 2011 and 2012 as an evaluating measure for the predictive maps. The model was applied to this data, including six incidents of wolf attack on humans and 16 incidents of attacks on livestock, to see whether they were correctly placed in high risk classes. 


\section{Results}

\subsection{Forecasting risk maps for wolf attack on humans and livestock}

The result of spatial correlation showed no significant correlation $\left(\chi^{2}=3.01 ; P<0.05\right)$ between wolf attacks on livestock and attacks on humans in HP. We generated risk maps indicating potential areas where wolf-human conflicts may occur throughout HP (Fig. 2). Our results showed that areas with a high probability of wolf-human conflict were located mostly in Bahar and Kaboudarahang counties, where most of the wolf attack data were collected. According to our results, Maxent generally performed better in predicting the potential distribution of wolf attacks on humans (average AUC $=0.920 ; \mathrm{SD}=0.013$ ) compared to attacks on livestock (average $\mathrm{AUC}=0.862 ; \mathrm{SD}=0.078$ ) and indicated high levels of predictive power and accuracy for both human and livestock models. We categorized the continuous probability map to five equal-sized probability classes. The resulting maps revealed that $10.9 \%$ and $15.65 \%$ of the study area was affected by high risk (classes 4 and 5) of wolf attack to humans and livestock, respectively (Table 1).

Testing the models with attack data from 2011 and 2012 showed that our models accurately assigned high probabilities (classes 4 and 5) of wolf attack to five test points for attacks on humans (83\%) and 12 test points for attacks on livestock (75\%) (Fig. 2), verifying the good performance of the model and its ability to be used as a valid tool for management of wolfhuman conflicts.

\subsection{Environmental factors}

Our results revealed that the most important environmental variable in predicting wolf attack on humans was the proportion of irrigated farms (Fig. 3a; $18.5 \%$ of contribution). The next most 
important variables were human population density (16.7\% of the contribution), roughness (14.9\%), denning probability (11.4\%) and distance to waterway (9\%) (Fig. 3a). Furthermore, for wolf attack on livestock, distance to settlements ( $31 \%$ of contribution), distance to protected areas $(11.8 \%)$, denning probability $(9.4 \%)$, proportion of dry farms $(8.8 \%)$ distance to waterway (8.2\%) were identified as the most important variables in determining high risk areas (Fig. 3b).The results of jackknife test indicated that the environmental variables with highest gain when used in isolation as well as variables that decreased the gain the most when omitted included proportion of irrigated farms, human population density, roughness, denning probability and distance to waterways for attacks on humans (Fig. 3c) and distance to settlements, distance to protected areas, denning probability and dry farms for attacks on livestock (Fig. 3d).

Response curves produced for Maxent Models show the direction of the effect of the most important parameters on wolf attacks (Fig. 4). We found that probability of wolf attacks on humans increased in areas with higher proportion of irrigated farms and high human density. Inversely, in areas with higher probability of den site selection by wolf and more roughed landscape probability of wolf attacks on human will be decreased. The response curves also indicated that wolf attacks on humans mostly occurred in the vicinity of settlements and waterways with an associated high standard deviation in areas further from settlements and waterways (Fig. 4). For attacks on livestock our results indicate that wolf attacks sharply decreased with an increase in distance from settlements and higher probability of den site selection by wolves, while increased in areas further from protected areas with higher proportion of dry farms (but with a high standard deviation related to two last variables) (Fig. 4).

The comparison of land use types occurring in probability categories revealed that in categories with high probability of wolf attack, agricultural activities, especially irrigated farms were the 
main land use type. We found that with an increased probability of wolf attack on humans in probability classes, irrigated farms cover a greater percentage of high-risk areas. This trend reversed for rangeland, a land use type with the lowest level of human intrusion (Fig. 5).

\section{Discussion}

\subsection{Characteristics of wolf attack sites in the modified landscape of HP}

We built our models based on wolf attack reports made by local people and confirmed by DOE. Governors of rural districts are responsible for reporting conflict, both in the form of livestock depredation and attacks to humans, to higher sectors of the government. Because the compensation program for livestock depredation requires confirmation of wolf attack by DOE, local herders are determined to identify and report any livestock loss that might have been caused by wolves. This system ensures high rates of detection and reporting wolf-human conflicts in the country. Moreover, forest cover and rugged terrain, which lower the chance of correct detection of wolf attacks (Breck et al. 2011; Oakleaf et al. 2003), are not likely to cause problems in HP since forest cover is minimal and herbaceous vegetation facilitates detection in both plains and mountainous regions. Even so, there remain a few instances of human and livestock loss which have not been confirmed by DOE. These instances, in which no witnesses existed and no sign of the victim could be found, mostly included insufficiently monitored livestock and/or unattended children (DOE Hamedan Provincial Office, pers. Comm.)

Our models successfully identified various characteristics of the environment that make wolf attacks more probable in HP. Although we do not have a thorough knowledge of wolf distribution in HP, our results indicate that wolf presence in close proximity to anthropogenic elements of the landscape with higher density of humans is not only common, but, as seen in 
response curves (Fig. 4) have also lead to a majority of wolf-human conflicts. Wolves are generally believed to avoid populated regions, mostly retreating to natural areas and away from human settlements (Jędrzejewski et al. 2008; Kaartinen et al. 2005), but an aggregation of suitable resources in human-modified landscapes is enough to attracts wild carnivores to such areas (Wilson et al. 2006). Various spatial analyses of canid attack sites have shown that human population density or related parameters, such as land use change and habitat fragmentation, greatly increase the chance of predatory attacks in the vicinity of human settlements (Jhala 2003; Timm et al. 2004).

Our models mainly suggest that anthropogenic elements of the landscape and human alteration of natural habitats are responsible for the surge in wolf attacks in HP. Especially near Bahar and Kaboudarahang counties where most attacks have occurred, agricultural expansion in the last three decades has destroyed almost all natural forests, leaving nothing but degraded rangelands, steep bare slopes, and rocky mountains (Imani Harsini 2012). The only intact habitats and natural ungulate populations are found in protected areas. As distance to protected areas increases, the landscape becomes more human-dominated, with little or no natural habitats and natural prey populations. Wolves are therefore limited to areas where their most important needs, habitat and food, are seen to.

Crop fields, identified in our study as the most important factor affecting wolf attacks on humans, are especially important for wolves in HP due to provision of habitat and water. Small packs of two to five wolves are commonly seen in agricultural fields (Reported by rangers, DOE Hamedan provincial office). Moreover, wolves prefer to breed in farms subject to low human disturbance and good water availability (José Vicente López-Bao, 2013; pers. Comm.), a condition that is provided in agricultural fields in HP. These fields also provide suitable cover for 
wolves to make their attacks on unattended children. Children are temporarily left unattended in such farms in HP while their parents work, providing a chance for wolves to attack and take the child. Similar events have been encountered in modified landscapes in India where large carnivores, concealed in tall crops, approached and attacked humans (Athreya et al. 2013).

Wolves are drawn to human settlements where their only abundant food sources, garbage and livestock, are abundant, thus the chance of predatory attacks in these areas increases (Jhala 2003; Timm et al. 2004). We identified nearness to human settlements as an important factor in wolf attacks to livestock and high population density having a high contribution to attacks on humans. Improper waste disposal methods practiced in HP (Hasanzadeh et al. 2012), as well as the availability of livestock near villages, attract hungry wolves to the outskirts of villages and towns. Wolves in these situations are easily habituated to humans (Eggermann et al. 2011; Krithivasan et al. 2009; Llaneza et al. 2012) and consequently more prone to showing predatory behavior towards them (Linnell et al. 2002; Mech and Boitani 2010; Sillero-Zubiri and Switzer 2004).

Moreover, most attacks to humans have occurred in flat plains with low roughness (Fig. 4), which are the most suitable lands for agriculture, especially irrigated farming. However, the relatively low importance of roughness for prediction of attacks on livestock (Fig. 3b, 3d) indicates that livestock depredation is likely to happen in lands with a variety of topographic features. This can be related to the method of livestock herding in HP where herders lead the herds to a variety of low plains and mountainous regions and highlands.

Although interpretation of our results is hampered by a lack of wolf pack distribution data in HP, the use of denning probability as an index of distribution of reproductive wolf packs in the region 
indicated that although this variable was an important predictor in wolf attacks to both humans and livestock (Fig. 3), the probability of attacks in areas with high probability of wolf denningflat plains with low human disturbance (Ahmadi et al. 2013)- is lower (Fig. 4). This might be because wolves tend to locate dens in areas with higher natural prey availability, or that since safety is an important feature of den locations, they avoid conflicts in these regions and concentrate their predatory behavior in areas away from dens. Further research is needed to confirm these possible explanations.

Vicinity to waterways also had considerable contribution to our risk map both for humans and livestock. Water is an important factor for wolf den site selection during lactation (Ahmadi et al. 2013). Wolf attacks on livestock and humans in HP are concentrated between late spring and early summer (Behdarvand \& Kaboli, in press). This timing, recorded commonly for predatory wolf attacks in several other countries (Linnell et al. 2002), corresponds to when wolves face a surge in dietary needs, as they start to give birth, nurse their young, and feed their pups (Edge et al. 2011).

\subsection{Conflict mitigation implications}

Our spatial risk models show the conflict hotspots in HP and can be of great help to the local government for planning conflict mitigation strategies. The conflict hotspots should be where the local government and future researchers focus their efforts and resources to implement and test the effectiveness of a variety of non-lethal wolf control methods (Breck et al. 2002; Breitenmoser et al. 2005; Gehring et al. 2006; Shivik 2004; Shivik and Martin 2000) and/or selective removal of problematic individuals (Treves et al. 2011; Treves et al. 2009). 
Generally, local people in HP lack the necessary knowledge regarding how to prevent encounters with the wolf and what actions to take when such encounters happen, believing that persecution is the only effective way to reduce conflicts. By considering the important factors that lead to conflicts in HP, it is now possible for the local government to provide relevant guidelines to avoid conflicts, both for livestock herders and local people in the high-risk areas. Since children are the primary target of wolves (Behdarvand \& Kaboli, in press), it is especially important to refrain from keeping children unattended in farmlands as well as in outskirts of towns and villages. Especially it is advisable not to recruit children as farm workers and herders.

Herding practices are in part responsible for predatory attacks, especially to livestock types that are allowed to graze freely (Iftikhar Dar et al. 2009; Sangay and Vernes 2008). HP local government and DOE should caution sheep herders in conflict hotspots about herding practices and especially encourage the use of a number of experienced shepherds and trained guard dogs of suitable breeds (Gehring et al. 2011; Tuğ 2005) to protect the herds and ensure effective monitoring. Moreover, since nearness to waterways increases the risk of depredation, herders should be given advice on provision of drinking water and monitoring herds during visits to natural streams.

Despite the ability of wolves to persist in agroecosystems, with much of the landscape being devoted to agricultural and livestock activities, (Schuette et al. 2013; Treves et al. 2011), humanwolf encounters and conflicts can also increase, for instance, owing to a low availability of wild prey. The best possible mitigation method for livestock depredation in situations similar to that of HP would be to restore the populations of wild prey (Sidorovich et al. 2003; Vos 2000), which, due to the loss of natural habitats, doesn't seem to be feasible in HP. More research is 
needed to consider the possibility of reintroducing natural prey such as hares (Lepus europaeus) that can survive in the modified landscape of HP.

The modeling method we used can be applied in other countries where biological data is lacking to map human-carnivore conflict and identify the most risk-prone areas where conservation and management resources should be allocated. The mitigation suggestions that we provided can be highly relevant for any region facing human-carnivore conflict in similar modified landscapes. The success of these methods can be significant in reducing negative attitudes toward carnivores and thus contribute to effective carnivore conservation.

\section{Acknowledgments}

This study was funded by the Department of Environment, Hamedan Provincial Office. We thank the rangers of DOE in HP who provided valuable guidance throughout the fieldwork. We are also grateful to Razieh Alemi, Azita Farashi, Jalil Imani, and Rasoul Khosravi for providing useful information to carry out the analyses and interpreting the results of this study and to Dr. Jose Vicente Lopez-Bao for commenting on an earlier version of this manuscript. 


\section{References}

Ahmadi, M., Kaboli, M., Nourani, E., Alizadeh Shabani, A., Ashrafi, S., 2013. A predictive spatial model for gray wolf (Canis lupus) denning sites in a human-dominated landscape in western Iran. Ecological Research, 513-521.

Athreya, V., Odden, M., Linnell, J.D., Krishnaswamy, J., Karanth, U., 2013. Big cats in our backyards: Persistence of large carnivores in a human dominated landscape in India. PloSone 8, e57872.

Belongie, C.C., 2008. Using GIS to create a gray wolf habitat suitability model and to assess wolf pack ranges in the western upper Peninsula of Michigan. Resource Analysis 10.

Bostedt, G., Grahn, P., 2008. Estimating cost functions for the four large carnivores in Sweden. Ecological Economics 68, 517-524.

Breck, S.W., Kluever, B.M., Panasci, M., Oakleaf, J., Bergman, D.L., Ballard, W., Howery, L., 2011. Factors affecting predation on calves and producer detection rates in the Mexican wolf recovery area. Biological Conservation 144, 930-936.

Breck, S.W., Williamson, R., Niemeyer, C., Shivik, J.A., 2002. Non-lethal radio activated guard for deterring wolf depredation in Idaho: Summary and call for research. USDA National Wildlife Research Center-Staff Publications, 467.

Breitenmoser, U., Angst, C., Landry, J.-M., Breitenmoser-Wursten, C., Linnell, J.D., Weber, J.M., 2005. Non-lethal techniques for reducing depredation, In People and Wildlife: Conflict or Co-existence? eds R. Woodroffe, S. Thirgood, A. Tabinowitz, pp. 49-71. Cambridge University Press, Cambridge, UK. 
Ciucci, P., Boitani, L., 1998. Wolf and dog depredation on livestock in central Italy. Wildlife Society Bulletin, 504-514.

Edge, J., Beyer Jr, D., Belant, J., Jordan, M., Roell, B., 2011. Livestock and domestic dog predations by wolves in Michigan. Human-Wildlife Interactions 5, 66-78.

Eggermann, J., da Costa, G.F., Guerra, A.M., Kirchner, W.H., Petrucci-Fonseca, F., 2011. Presence of Iberian wolf (Canis lupus signatus) in relation to land cover, livestock and human influence in Portugal. Mammalian Biology 76, 217-221.

Elith, J., Phillips, S.J., Hastie, T., Dudík, M., Chee, Y.E., Yates, C.J., 2011. A statistical explanation of MaxEnt for ecologists. Diversity and Distributions 17, 43-57.

ESRI INC, 2008. ArcGIS 9.3. Environmental Systems Research Institute, Redlands. Gehring, T.M., Hawley, J.E., Davidson, S.J., Rossler, S.T., Cellar, A.C., Schultz, R.N., Wydeven, A.P., VerCauteren, K.C., 2006. Are viable non-lethal management tools available for reducing wolf-human conflict? Preliminary results from field experiments, In Proceedings of the 22nd Vertebrate Pest Conference. pp. 2-6, California, USA.

Gehring, T.M., VerCauteren, K.C., Provost, M.L., Cellar, A.C., 2011. Utility of livestockprotection dogs for deterring wildlife from cattle farms. Wildlife Research 37, 715-721.

Graham, K., Beckerman, A.P., Thirgood, S., 2005. Human-predator-prey conflicts: ecological correlates, prey losses and patterns of management. Biological Conservation 122, 159-171. Gurung, B., Smith, J.L.D., McDougal, C., Karki, J.B., Barlow, A., 2008. Factors associated with human-killing tigers in Chitwan National Park, Nepal. Biological Conservation 141, 3069-3078. Hasanzadeh, M., Kaboli, M., Khosravi, R., Ahmadi, M., 2012. The investigation of relation between waste composition, wolf (Canis lupus) and their conflicts with native people in 
Hamedan province. Journal of Natural Environment, Iranian Journal of Natural Resources 65, 45-52.

Hernandez, P.A., Graham, C.H., Master, L.L., Albert, D.L., 2006. The effect of samle size and species characteristics on performance of differenct species distribution modeling methods. Ecography 29, 773-785.

Holmern, T., Nyahongo, J., Røskaft, E., 2007. Livestock loss caused by predators outside the Serengeti National Park, Tanzania. Biological Conservation 135, 518-526.

Iftikhar Dar, N., Minhas, R.A., Zaman, Q., Linkie, M., 2009. Predicting the patterns, perceptions and causes of human-carnivore conflict in and around Machiara National Park, Pakistan. Biological Conservation 142, 2076-2082.

Imani Harsini, J., 2012. Study the change detection land use/ cover in Hamedan province considering wolves potential habitats during the past 30 years. University of Tehran, Tehran, Iran.

Jhala, Y.V., 2003. Status, ecology and conservation of the indian wolf Canis lupus pallipes Sykes. Journal of Bombay Natural History Society 100, 293-307.

Jones, K.E., Patel, N.G., Levy, M.A., Storeygard, A., Balk, D., Gittleman, J.L., Daszak, P., 2008. Global trends in emerging infectious diseases. Nature 451, 990-993.

Kaartinen, S., Luoto, M., Kojola, I., 2009. Carnivore-livestock conflicts: determinants of wolf (Canis lupus) depredation on sheep farms in Finland. Biodiversity and Conservation 18, 35033517.

Khosravi, R., Rezaei, H.R., Kaboli, M., 2013. Detecting Hybridization between Iranian Wild Wolf (Canis lupus Pallipes) and Free-Ranging Domestic Dog (Canis familiaris) by Analysis of Microsatellite Markers. Zoological Science 30, 27-34. 
Krithivasan, R., Athreya, V., Odden, M., 2009. Human-wolf conflict in human dominated landscapes of Ahmednagar District, Maharashtra. Rufford Small Grants Foundation for Nature Conservation, 1-53.

Larsen, T., Ripple, W., 2006. Modeling Gray Wolf (Canis lupus) habitat in the Pacific Northwest, U.S.A. . Journal of Conservation Planning 2, 17-33.

Linnell, J.D.C., Andersen, R., Andersone, Z., Balciauskas, L., Blanco, J.C., Boitani, L., Brainerd, S., Breitenmoser, U., Kojola, I., Liberg, O., 2002. The fear of wolves: A review of wolf attacks on humans. NINA Oppdragsmelding 731, 1-65.

Linnell, J.D.C., Solberg, E.J., Brainerd, S., Liberg, O., Sand, H., Wabakken, P., Kojola, I., 2003. Is the fear of wolves justified? A Fennoscandian perspective. Acta Zoologica Lituanica 13, 2733.

Linnell, J.D.C., Swenson, J.E., Anderson, R., 2001. Predators and people: conservation of large carnivores is possible at high human densities if management policy is favourable. Animal Conservation 4, 345-349.

Llaneza, L., López-Bao, J.V., Sazatornil, V., 2012. Insights into wolf presence in humandominated landscapes: The relative role of food availability, humans and landscape attributes. Diversity and Distributions 18, 459-469.

Löe, J., Röskaft, E., 2004. Large carnivores and human safety: A review. Ambio 33, 283-288. McNay, M.E., Hicks, M.V., 2002. A case history of wolf-human encounters in Alaska and Canada. Alaska Department of Fish and Game, Wildlife Technical Bulletin 13. Mech, L.D., Boitani, L., 2010. Wolves: behavior, ecology, and conservation. University of Chicago Press, Chicago, USA. 
Michalski, F., Boulhosa, R., Faria, A., Peres, C., 2006. Human-wildlife conflicts in a fragmented Amazonian forest landscape: determinants of large felid depredation on livestock. Animal Conservation 9, 179-188.

Mishra, C., 1997. Livestock depredation by large carnivores in the Indian trans-Himalaya: conflict perceptions and conservation prospects. Environmental Conservation 24, 338-343. Mladenoff, D.J., Sickley, T.A., Wydeven, A.P., 1999. Predicting gray wolf landscape recolonization: Logistic regression models vs. new field data. Ecological Applications 9, 37-44. Muhly, T.B., Musiani, M., 2009. Livestock depredation by wolves and the ranching economy in the Northwestern US. Ecological Economics 68, 2439-2450. Norris, D.R., Theberge, M.T., Theberge, J.B., 2002. Forest composition around wolf (Canis lupus) dens in eastern Algonquin Provincial Park, Ontario. Canadian Journal of Zoology 80, 866872.

Northrup, J., Stenhouse, G., Boyce, M., 2012. Agricultural lands as ecological traps for grizzly bears. Animal Conservation 15, 369-377.

Oakleaf, J.K., Mack, C., Murray, D.L., 2003. Effects of wolves on livestock calf survival and movements in central Idaho. Journal of Wildlife Management 67, 299-306.

Pearson, R.G., Raxworthy, C.J., Nakamura, M., Townsend Peterson, A., 2007. Predicting species distributions from small numbers of occurrence records: a test case using cryptic geckos in Madagascar. Journal of Biogeography 34, 102-117.

Phillips, S.J., Anderson, R.P., Schapire, R.E., 2006. Maximum entropy modeling of species geographic distributions. Ecological Modelling 190, 231-259.

Phillips, S.J., Dudík, M., 2008. Modeling of species distributions with Maxent: new extensions and a comprehensive evaluation. Ecography 31, 161-175. 
Reyahi Khoram, M., Fotros, M., 2011. Land use planning of Hamadan province by means of GIS, In Proceedings of the International conference on chemical, biological and environment sciences. pp. 400-404, Bangkok, Thailand.

Sacks, B.N., Blejwas, K.M., Jaeger, M.M., 1999. Relative vulnerability of coyotes to removal methods on a northern California ranch. The Journal of Wildlife Management 63, 939-949. Sangay, T., Vernes, K., 2008. Human-wildlife conflict in the Kingdom of Bhutan: Patterns of livestock predation by large mammalian carnivores. Biological Conservation 141, 1272-1282. Schuette, P., Wagner, A.P., Wagner, M.E., Creel, S., 2013. Occupancy patterns and niche partitioning within a diverse carnivore community exposed to anthropogenic pressures. Biological Conservation 158, 301-312.

Shivik, J.A., 2004. Non-lethal alternatives for predation management. Goat Research Journal 19, 64-71.

Shivik, J.A., Martin, D.J., 2000. Aversive and disruptive stimulus applications for managing predation, In Proeedings of the Wildlife Damage Management Conference. pp. 111-119, Pennsylvania, USA.

Sidorovich, V.E., Tikhomirova, L.L., Jedrzejewska, B., 2003. Wolf Canis lupus numbers, diet and damage to livestock in relation to hunting and ungulate abundance in northeastern Belarus during 1990-2000. Wildlife Biology 9, 103-111.

Sillero-Zubiri, C., Switzer, D., 2004. Management of wild canids in human-dominated landscapes. Canids: foxes, wolves, jackals and dogs. Status survey and conservation action plan. 2 Edición. IUCN Canid Specialist Group, Gland, Switzerland and Cambridge, UK, 257-266. 
Timm, R.M., Baker, R.O., Bennett, J.R., Coolahan, C.C., 2004. Coyote attacks: An increasing suburban problem, In Proceeding of the 21st Vertebrate Pest Conference. pp. 47-57, California, USA.

Trapp, J.R., Beier, P., Mack, C., Parsons, D.R., Paquet, P.C., 2008. Wolf, Canis lupus, den site selection in the Rocky Mountains. The Canadian field-naturalist 122, 49-56.

Treves, A., Karanth, K.U., 2003. Human - carnivore conflict and perspectives on carnivore management worldwide. Conservation Biology 17, 1491-1499.

Treves, A., Martin, K.A., Wydeven, A.P., Wiedenhoeft, J.E., 2011. Forecasting environmental hazards and the application of risk maps to predator attacks on livestock. Bioscience 61, 451458.

Treves, A., Naughton - Treves, L., Harper, E.K., Mladenoff, D.J., Rose, R.A., Sickley, T.A., Wydeven, A.P., 2004. Predicting human - carnivore conflict: A spatial model derived from 25 years of data on wolf predation on livestock. Conservation Biology 18, 114-125.

Treves, A., Wallace, R., White, S., 2009. Participatory planning of interventions to mitigate human-wildlife conflicts. Conservation Biology 23, 1577-1587.

Tuğ, S., 2005. Conflicts between humans and wolf: A study in bozdağ, konya province, Turkey. Middle East Technical University, Turkey.

Unger, D.E., Keenlance, P.W., Kohn, B.E., Anderson, E.M., 2009. Factors influencing homesite selection by gray wolves in northwestern Wisconsin and east-central Minnesota, In Recovery of Gray Wolves in the Great Lakes Region of the United States. pp. 175-189. Springer.

Venette, R.C., Kriticos, D.J., Magarey, R.D., Koch, F.H., Baker, R.H., Worner, S.P., Raboteaux, N.N.G., McKenney, D.W., Dobesberger, E.J., Yemshanov, D., 2010. Pest risk maps for invasive alien species: a roadmap for improvement. Bioscience 60, 349-362. 
Vos, J., 2000. Food habits and livestock depredation of two Iberian wolf packs (Canis lupus signatus) in the north of Portugal. Journal of Zoology 251, 457-462.

Wilson, S.M., Madel, M.J., Mattson, D.J., Graham, J.M., Merrill, T., 2006. Landscape conditions predisposing grizzly bears to conflicts on private agricultural lands in the western USA.

Biological Conservation 130, 47-59.

Wydeven, A.P., Treves, A., Brost, B., Wiedenhoeft, J.E., Fascione, N., Delach, A., Smith, M., 2004. Characteristics of wolf packs in Wisconsin: Identification of traits influencing depredation.

People and predators: From conflict to coexistence, 28-50.

Ziaie, H., 2008. A field guide to mammals of Iran, 2nd ed edn. Iran Wildlife Center, Tehran, Iran. 


\section{Table:}

Table 1 Area and percentage of probability classes with potential probability of wolf attack on humans and livestock within five equally classified P-values of Maxent models

\begin{tabular}{|c|c|c|c|c|}
\hline \multirow[b]{2}{*}{$\begin{array}{l}\text { Maxent probability } \\
\text { intervals }\end{array}$} & \multicolumn{2}{|c|}{ Attack on humans } & \multicolumn{2}{|c|}{ Attack on livestock } \\
\hline & $\%$ of area & $\begin{array}{l}\text { Area } \\
\left(\mathrm{km}^{2}\right)\end{array}$ & $\%$ of area & Area $\left(\mathrm{km}^{2}\right)$ \\
\hline $0-0.2$ & 55.52 & 10822.51 & 40.78 & 7950.02 \\
\hline $0.2-0.4$ & 21.93 & 4274.81 & 29.28 & 5902.61 \\
\hline $0.4-0.6$ & 11.62 & 2265.09 & 14.29 & 2980.56 \\
\hline $0.6-0.8$ & 6.35 & 1237.81 & 9.12 & 1581.87 \\
\hline $0.8-1$ & 4.57 & 890.83 & 6.53 & 1077.95 \\
\hline
\end{tabular}




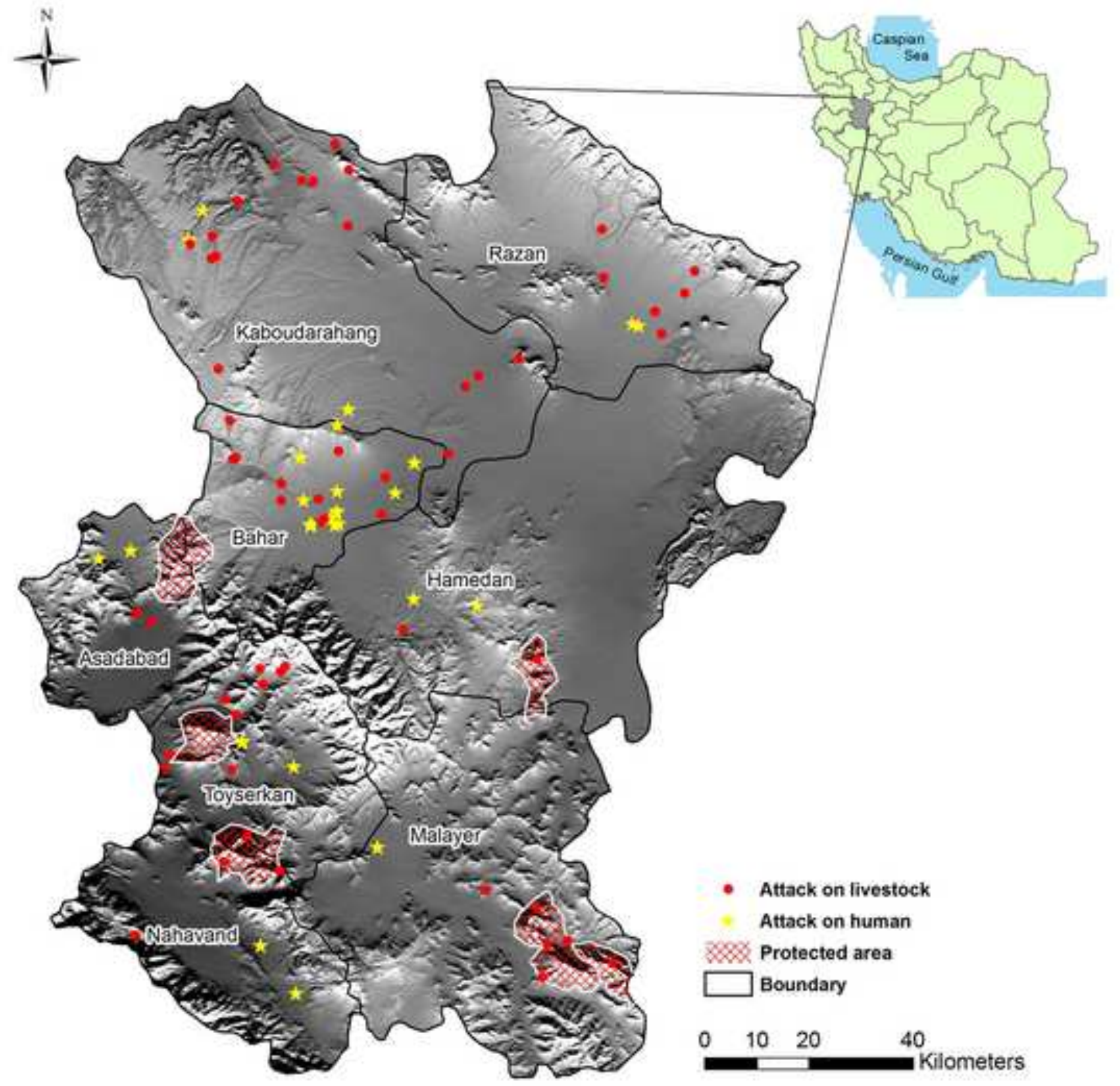



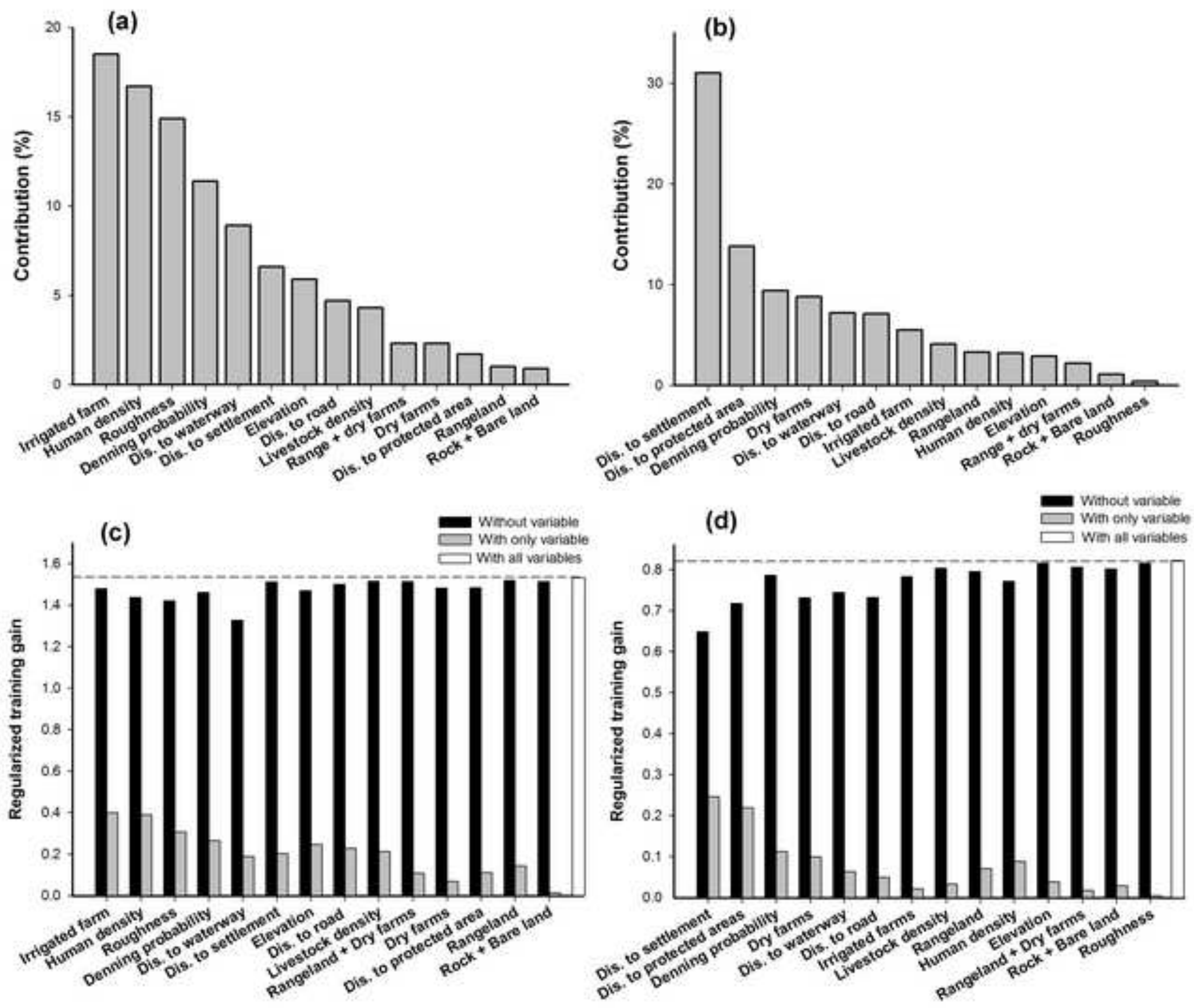


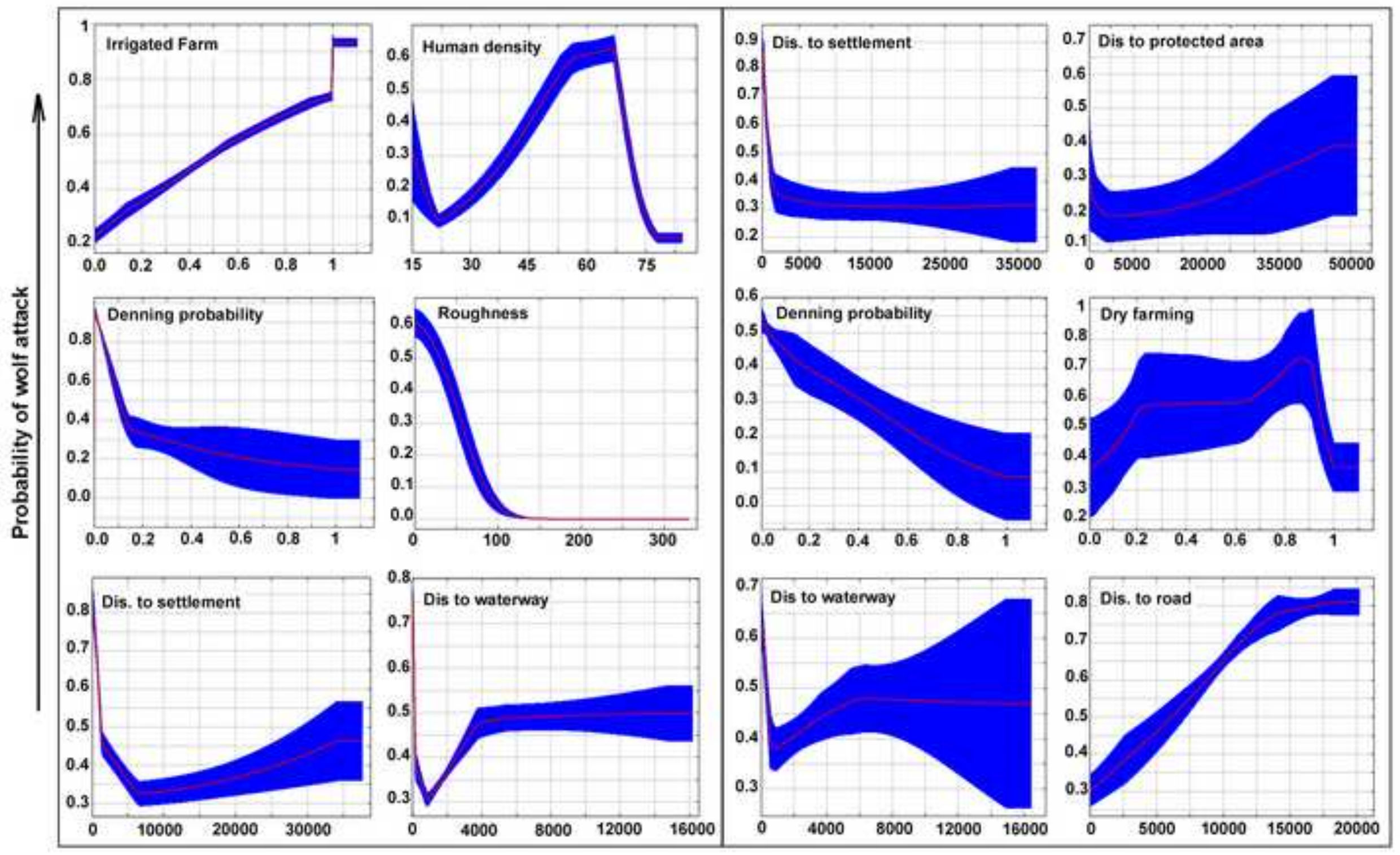



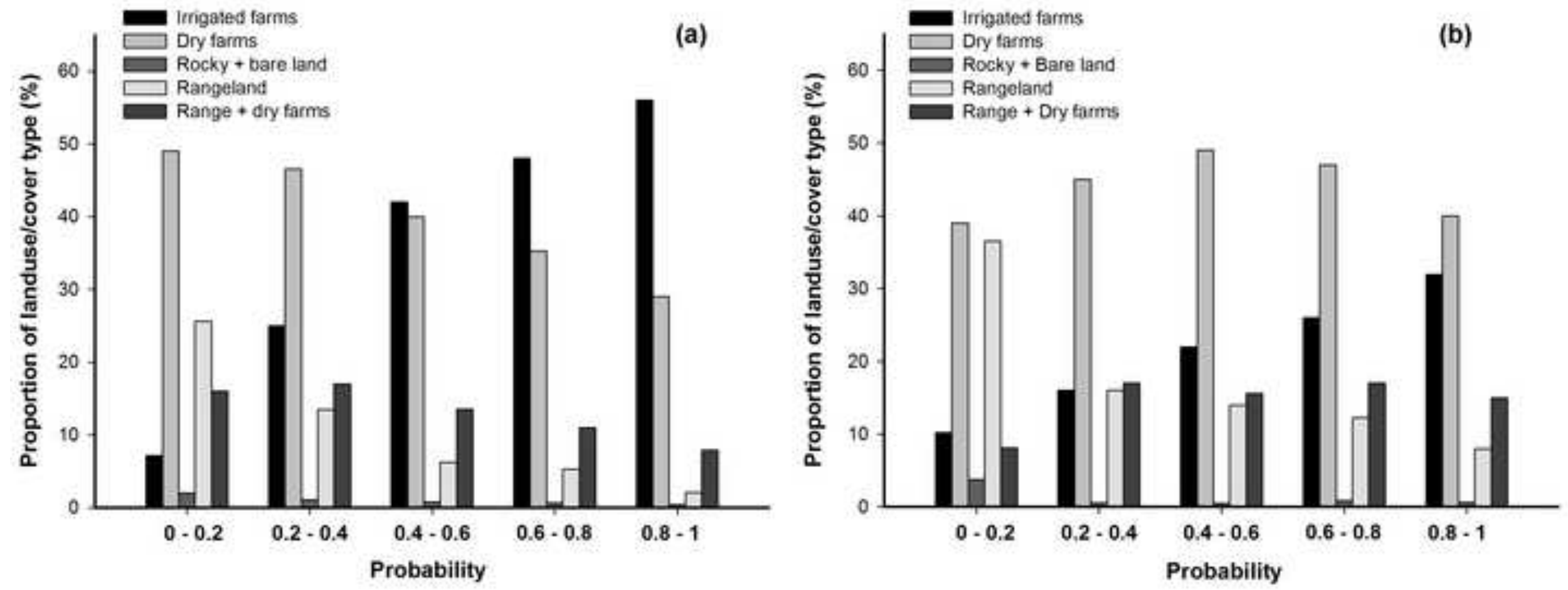


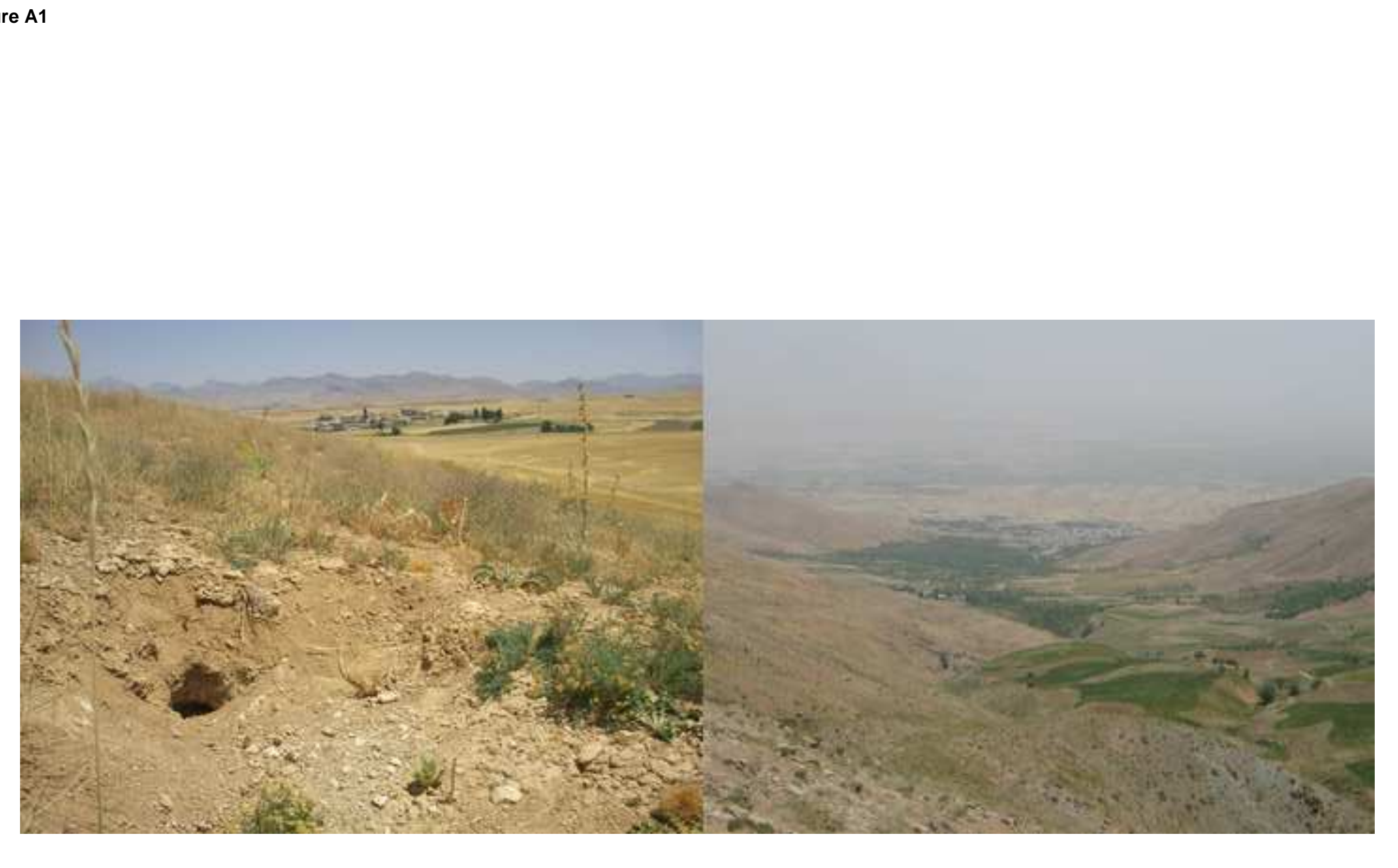

Figure A1
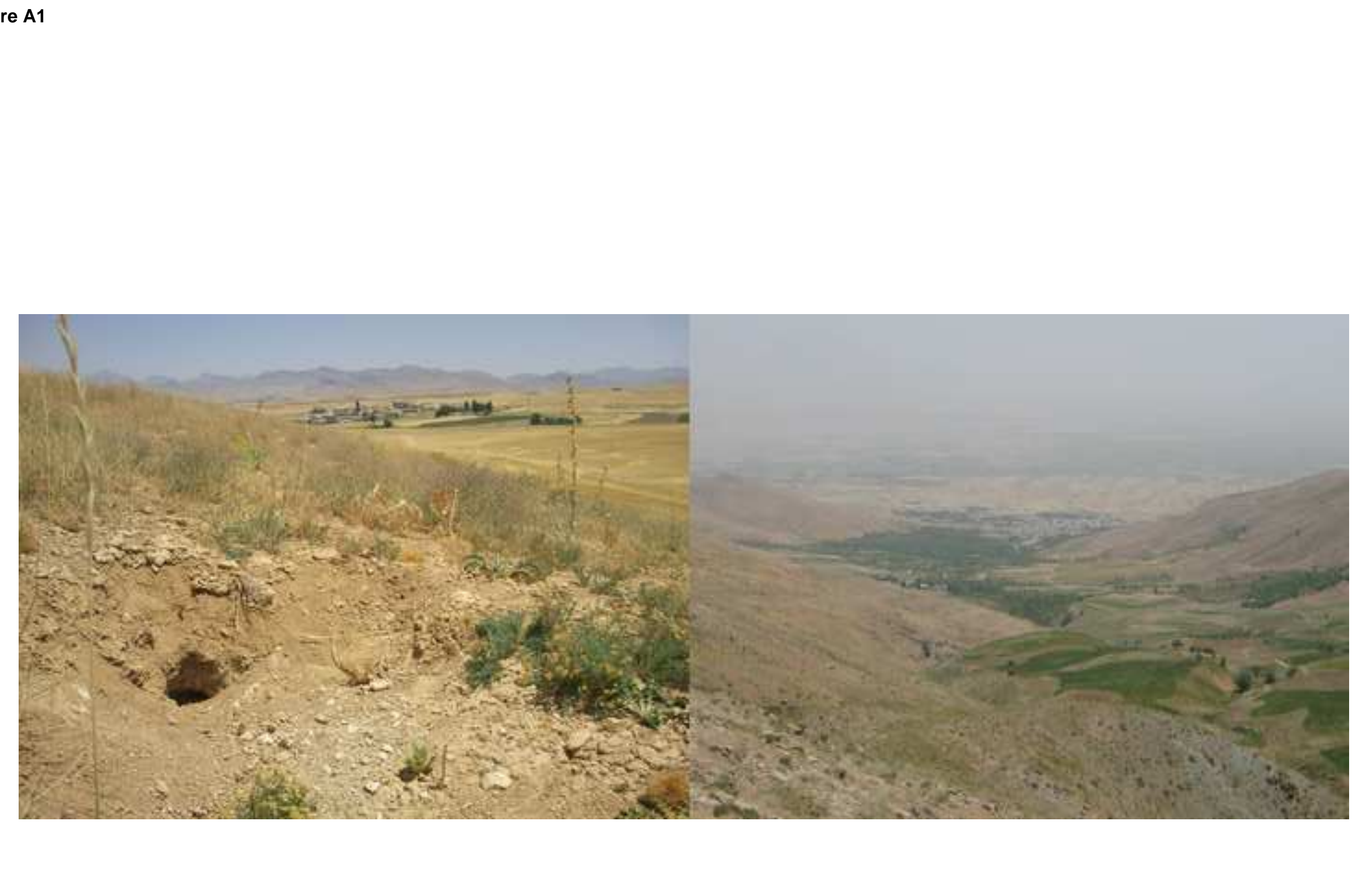

.
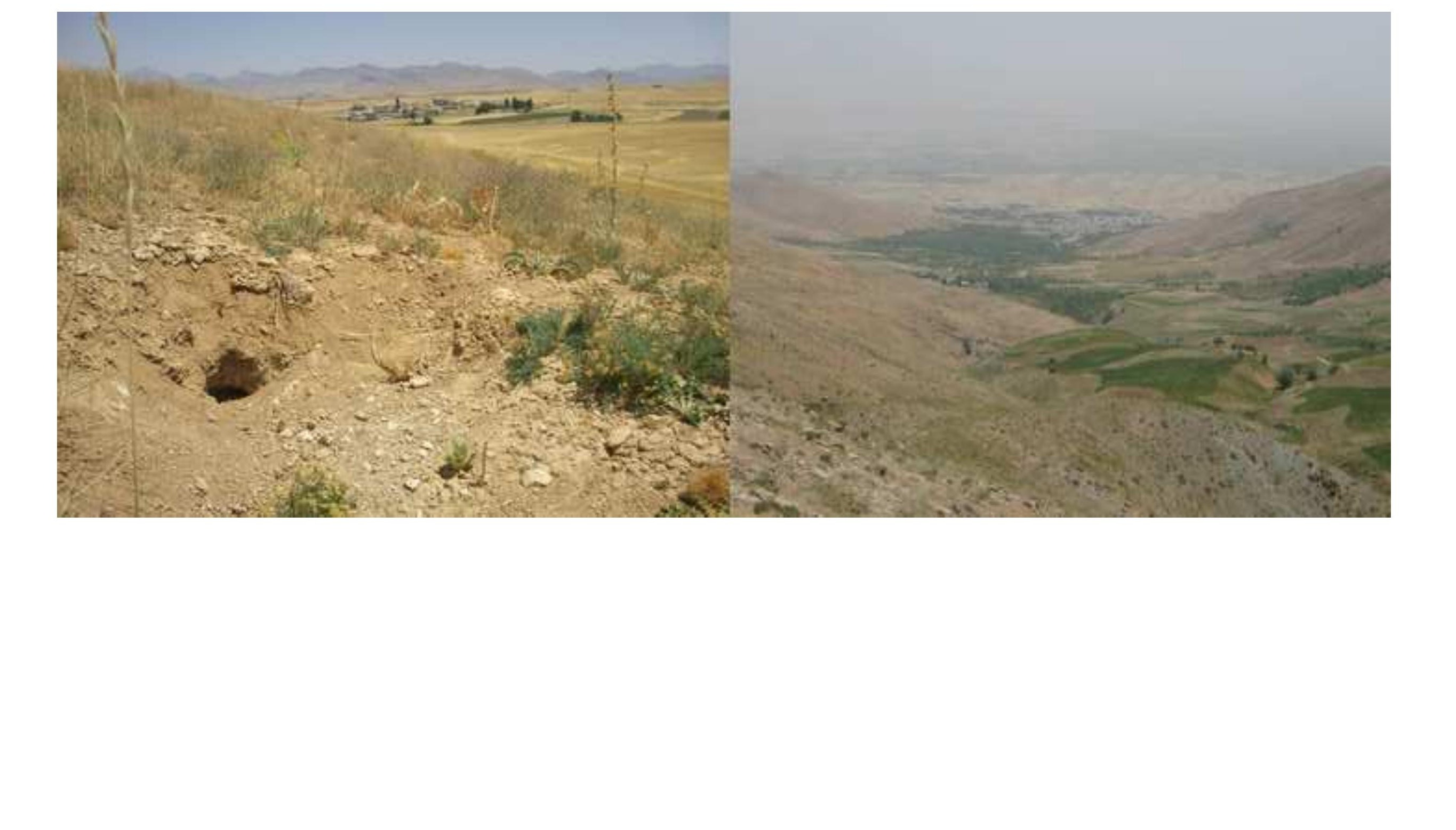